Чем выше был уровень обструкции, тем больше времени требовалось для санации мочевых путей, более замедленно стихал воспалительный процесс в почках: после операции на лоханочно-мочеточниковом сегменте - - более 1 года, на мочеточниково-пузырном -- несколько месяцев, на пузырно-уретральном - не более месяца.

При оперативном лечении обструктивных заболеваний органов мочевыведения в несколько этапов в послеоперационном периоде отмечалось постепенное нарастание числа инфицированных больных. В раннем послеоперационном периоде ведущая роль принадлежала синегнойной палоче и протею. При обструктивных заболеваниях органов мочевыведения, сопровождавшихся функциональной и морфологической гибелью почки, после нефрэктомии наблюдалось резкое снижение степени бактериурии с более полной санацией мочевой системы на отдаленных сроках. При дренировании мочевых путей на длительный срок резко возрастала вероятность реинфекции за счет госпитальных штаммов.

Тяжесть и течение микробно-воспалительного процесса в почках находились в прямой зависимости от степени нарушения уродинамики, а также от уровня и вида обструкции.

\title{
ЛИТЕРА ТУРА
}

1. Езерский $P$. Ф.//Пиелонефрит у детей.- Л., Медицина, 1977.-. 2. Игнатова М. С.// Урол. и нефрол.- 1982.- № 5.- С. 47-50.- 3. Люлько А. В./ Функциональное состояние и патология единственной почки.-- Киев, 1982.- 4. Люлько А. В., Мурзанидзе Д. Д., Возианов $A . \Phi . / /$ Основы практической урологии детского возраста.— Киев, 1984. -5. Михайлова 3. М. Педиатрия.-1982.- № 3.- С. 5-7.-6. Распутняк С. Г.//Урол. и нефрол.1985. - № 4.- С. 28-30.-7. Суркова Т. П., Валиуллина И. Д., Трепалина О. Л.//Характеристика микрофлоры при воспалительных заболеваниях органов мочевыведения у детей.М., Медицина, 1982.- 8. Суходольская А. E., Рудниченко А. В., Чайовская B. Л.//Урол. и нефрол.- 1978.- № 2.- С. 8-12.-9. Тиктинскии O. Л./Воспалительные неспецифические заболевания мочеполовых органов.-- Л., Медицина, 1984. - IO. Hoveliey B., Marclh P.A.// Rev. infect. Dis.-1984-Vol. 6.- P. 328-337-11. Sietzen W.//Ausg. A.- 1981.-Vol. $20 .-$ P. $10-13$.

Поступила 12.12 .86

\section{OБ30P}

УдК 576.8.097.3-02:618.33-001.31:616.8

\section{ИММУНОБИОЛОГИЧЕСКИЕ МЕХАНИЗМЫ ПЕРИНАТАЛЬНЫХ ПОРАЖЕНИЙ ЦЕНТРАЛЬНОЙ НЕРВНОЙ СИСТЕМЫ}

\author{
Б. Г. Садыков, Ю. И. Бородин
}

Кафедры акуиерства и гинекологии № 1 (зав.-- проф. Л. А. Козлов) и № 2 (зав.проф. Б. Г. Садыков) Казанского ордена Трудового Красного Знамени медицинского института имени С. В. Курашова

\begin{abstract}
Одной из ведущих проблем советского здравоохранения является антенатальная охрана плода и профилактика перинатальной заболеваемости и смертности. Главной причиной перинатальной летальности и тяжелых неврологических поражений в детском возрасте, по-прежнему выступает родовая черепно-мозговая травма [22]. Поэтому родовые повреждения новорожденных были и остаются актуальной проблемой неонатологии [12]. У 10$30 \%$ новорожденных в первые дни жизни имеется та или иная неврологическая симптоматика [29, 54]. По мнению А. Ю. Ратнера [30], натальные повреждения нервной системы в процессе родов возникают под влиянием не только чисто механических причин, но в большей степени и многочисленных антенатальных факторов, требующих в этом плане самого серьезного изучения. С таких позиций для психиатров и невропатологов особенно большой интерес представляет исследование иммунологического механизма внутриутробного повреждения мозга плода и новорожденного [44].

Известно, что иммунные реакции участвуют в нормальном процессе воспроизводства на всех его этапах. Между организмом матери и плода во время беременности возникают сложные иммунобиологические взаимоотношения, оказывающие определенное воздействие на течение беременности, развитие плода и новорожденного $[3,7,9-11,52]$.

Изучение иммунологических реакций организма при неосложненной и осложненной беременности позволяет понять патогенез ряда нарушений в системе мать - плацентаплод при различных видах акушерской патологии и связанной с ними перинатальной
\end{abstract}


заболеваемости, разработать новые подходы к диагностическим, профилактическим и терапевтическим мероприятиям |8, $31 \mid$.

Исследования последних лет показывают, что при нжоторық нервно-психических заболеваниях имеет место появление антител к мозгу в крови білыных $|21,39,41,57|$.

Возможность образования протиномозговых антител объясняется относительной чужеродностью мозга для всего ортанизма в целом, обусловленной его ранним обособлением от иммуногенетических систем в процессе эмбриогенеза. Это создает условия для проявления его высоких органоспецифических свойств и возникновения аутоиммунных процессов Г26, $53,55)$. Наряду с антигенами, характеризующими иммунологическую специфичность мозга как органа в целом, мозговая ткань содержит антигены, общие с другими тканями организма, такими как печень, почки, селе'зенка, сердце, тимус и др. |5, 40|. Были установлены следующие типы антигенов в человеческом эмбриональном мозге: а) антигены, общие для эмбрионального мозга и для других органов того же эмбрионального периода (печени, почек, легкого, кожи, желудочно-кишечного тракта); б) антигены, обшие для эмбрионального мозга и для некоторых органов взрослого человека (мозга, яичка, селезенки, печени, почки, легкого); в) фазово (стадийно)-специфические антигены мозга, характерные только для эмбрионального периода с 8 по 10 нед. Показано присутствие в мозговой ткани $\rightarrow$-антигена, свойственного поверхностям тимоцитов, что делает иммуногенные свойства нервной ткани уникальными [6]. С помощью современных методов исследования стало возможным дифференцировать в антигенном отношении серое и белое вещество головного мозга, а также различные отделы ЦНС и отдельные структурные элементы [5, 55, 56]. Особого внимания заслуживают данные о том, что значительная часть известных специфических белков мозга (S-100, GFAP, $\alpha_{2}$-гликопротеид и др.) локализована в глии $|13|$. Специфическая сенсибилизация мозговым антигеном выражается активацией ультраструктур как в нервных, так и в глиальных элементах мозговой ткани [49].

Разработан метод получения антиглиальных и антинейрональных иммунных гаммаглобулинов, специфически реагирующих с антигенами клеток глии и нейронов и избирательно нарушающих их функции $[25,27]$. Авторы считают, что первоначальное поражение глиальных элементов иммунного генеза может быть причиной развития некоторых психических заболеваний (эпилепсия).

Исследования әффекта противомозговых антител в культуре нервной ткани, данные об их действии на развитие экспериментального аллергического энцефаломиелита указывают на дейстии на развитие эксперименто агрессивную роль антител, вызывающих повреждение нервной ткани |l6, 18, 28, 33], либо защитное действие противомозговых антител [1]. Разнонаправленность действия противомозговых антител зависит от характера, интенсивности и продолжительности антигенной стимуляции, стадии патологического процесса, состояния иммунобиологической реактивности организма, обусловливая защитный или повреждающий эффект [55].

Установлена роль нейроиммунного конфликта в патогенезе нарушений формирования мозга плода, развития деструктивно-атрофических процессов в нем при беременности [3748]. В связи с актуальностью и значимостью этих исследований на IV Международном симпозиуме по иммунологии репродукции, проходившем в 1978 г. в г. Варне, нейроиммунология была выделена в самостоятельное направление иммунологии воспроизводства [4].

Клинико-иммунологические исследования и результаты моделирования на животных показывают важную роль нейроиммунных механизмов в патогенезе врожденных нервно-психических заболеваний $[40,45-47]$.

Установлено, что у $75 \%$ детей, родившихся с антителами к мозгу в крови, наблюдаются различные заболевания нервной системы. Они возникают у них в 6-8 раз чаще, чем у детей, имеющих такой же тяжелый анамнез, но родившихся без антител к мозгу в крови [14]. По мнению ряда авторов, нейроиммунный конфликт в системе мать-плод может являться непосредственной причиной пренатальной церебральной патологии, указывать на возможность нарушения развития ЦНС у плода $135,37,47,48\}$.

Исследования, проведенные Н. Т. Зубцовой [14], свидетельствуют о возможности появления нейроиммунного конфликта, в особенности при осложненной беременности (токсикозы, угроза преждевременных родов, анемия, гипертония и др.). При этом выявлены антитела как к гетерологичному мозгу крысы (чаще), так и антитела к антигенам гомологичного мозга (зрительный бугор, белое вещество, серое вещество коры мозга, хвостатое ядро, мозжечок). Тем самым отмечена возможность избирательного аутоиммунного поражения мозга плода $[14,48]$.

С помощью экспериментальной модели нейросенсибилизации, созданной путем введения гомологичных мозговых антигенов беременной самке (крысе), установлено патогенное влияние нейросенсибилизации беременной матери на внутриутробное и постнатальное развитие ЦНС потомства, что имеет непосредственное отношение к пониманию врожденной патологии человека $[37,38,51]$. Исследования показали, что различные структуры мозга, послужившие антигенами для сенсибилизации, вызывают различные нарушения поведения у новорожденных животных $[35,37]$.

Сенсибилизация гомологичными мозговыми антигенами беременной самки удлиняет сроки беременности, ведет к понижению жизнеспособности или гибели части плодов и крысят после рождения, к разнообразным уродствам и функциональным расстройствам ЦНС [42]. Отмечены парезы, нарушения координации движений у новорожденных при сенсибилизации самки антигенами продолговатого мозга [34]. Повышение судорожной готовности потомства выявлено и при сенсибилизации самок крыс антигенами различных отделов мозга до беременности [51]. Следовательно, однажды возникшая сенсибилизация мозговыми антигенами создает условия для дальнейшей аутосенсибилизации беременного животного [42].

19. “Казанский медицинский журнал» № 4. 
Значительный интерес представляют экспериментальные данные о влиянии сенсибилизации самки антигенами гомологичного мозга на состояние тимуса плода, свидетельствующие о непосредственном воздействии факторов нейроиммунного конфликта на ткани тимуса [36]

У потомства крыс, сенсибилизированных до беременности гомологичными антигенами серого вещества коры головного мозга, выявляются нарушение анте- и постнатального нейрогенеза, увеличение числа глиальных клеток и перинейроналыных сателлитов во все сроки постнатальной жизни, нарастание патологических изменений корковых нейронов. Эти изменения коррелируют с появлением в крови потомства аутоантител к мозгу [19, 43].

В экспериментах на крысах с помощью радиоизотопных методов было показано, что противомозговые антитела могут трансплацентарно проникать от матери к плоду и, прояляя определенную нейротропность, накапливаться в мозге. Недостаточная сформированность, незрелость гематоэнцефалического барьера в антенатальном периоде способствуют проникновению антител в мозг $[20,43,51]$.

Нейросенсибилизация животных антигенами определенных отделов мозга приводит к специфическому аутоиммунному воздействию на интенсивность биосинтеза функционально активных белков в соответствующих структурах ЦНС у потомства [50]. Родовой акт при нейросенсибилизации нередко осложняется слабостью родовой деятельности [15]. Работами ряда авторов установлено, что наиболее часто противомозговые антитела обнаруживаются у матерей, дети которых родились в асфиксии.

Таким образом, внутриутробная церебральная патология приводит к более частому возникновению асфиксии и родовой травмы даже при нормальных родах. Поражение ЦНС у плодов вызывает особо тяжелые последствия в постнатальном периоде $[2,14,23,24]$.

При обследовании беременных с резус-конфликтом и их новорожденных с гемолитической болезнью с помощью реакции связывания комплемента (РСК) на холоду и теста торможения миграции глии (ТМГ) была выявлена нейросенсибилизация при изоиммунизированной беременности [32]. Противомозговые антитела обнаруживались с $6-7$ нед и затем на протяжении всей беременности в крови рожениц и новорожденных. Антитела к мозгу, определяясь с неодинаковой частотой в течение беременности в зависимости от формы гемолитической болезни плода и новорожденных, обнаружены при резус-конфликтной беременности с помощью PCK в $63,2 \pm 2,7 \%$ случаев, ТМГ-в $94,2 \pm 1,3 \%$. При этом в третьем триместре частота серопозитивных результатов в РСК составила $75,2 \pm 3,9 \%$. Антиглиальные антитела были найдены перед родами у всех беременных. По-видимому, выявленные с помощыю нейроиммунологических тестов противомозговые антитела являются показателями поражения формирующегося мозга плода при иммуноконфликтной беременности и служат, по мнению авторов, ранним диагностическим критерием возможных родовых черепно-мозговых травм и неврологических расстройств у детей, а это позволяет приступать к своевременной корригирующей терапии еще при беременности. Применение комплексной терапии изосенсибилизированным беременным, а также выбор оптимального срока родоразрешения с учетом нейроиммунологических показателей привели к снижению перинатальной смертности от этого заболевания со $163 \%$, в 1973 г. цо $75 \%$ в 1983 г. [1 7]

Таким образом, полученные данные свидетельствуют о возникновении при изоиммунизированной беременности аутоиммунных сдвигов в системе мать - плацента - плод и появлении в результате этого нейросенсибилизации организма беременной. Кроме того, правомочно мнение о возможном участии иммунобиологических механизмов в развитии перинатальных поражений центральной нервной системы новорожденных и детей.

\section{ЛИТЕРАТУРА}

1. Акимов Г. А., Шамрей Р. К., Зинченко А. П., Головкин В. И. // В кн.: Иммунопатологя нервных и психических заболеваний. Тез. докл. Всесоюзн. научн. конф.- М., 1983.2. Батманова В. В.// В кн.: Актуальные вопросы неврологии и нейрохирургии новорожденных. Тез. Всерос. симпоз.- Новокузнецк, 1980.-3. Братанов К. // В кн.: Современные проблемы иммунологии репродукции.- Тез. докл. I Всесоюзн. симпоз.- Новосибирск, 1977.- 4. Братанов K. В кн.: Иммунология репродукции.- Труды IV Международн. симпоз.- Варна - София, 1979.-5. Бурбаева Г. Ш., Лозовский Д. В.// Вестн. АМН СССР. 1971.- № 1.- С. 50-55.-6. Вартанян M. E./ Там же.-1974.- № 1.-C. 51-57.-7. Ba-

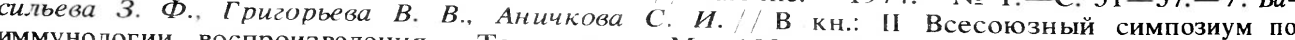
иммунологии воспроизведения.- Тез. докл.- М., 1980.-8. Васильева З. Ф., Башмакова М. А. // В кн.: Иммунопатология нервных и психических заболеваний.- Тез. докл. Всесоюзн. научн. конф.- М., 1983.- 9. Волкова Л. С.//Иммунобиологические взаимоотношения организмов матери и плода.- М., Медицина, 1970.- IO. Вязов О. Е., Вербицкий М. Ш., оз - Вар. Иммунология размножения. - Труды III Международн. симпоз.- Варна - София, 1978.- 11. Головистиков И. Н.// В кн.: Итоги науки и техники ВИНИТИ АН СССР.- Сер. Иммунология.- 1979.- Т. 8.- С. 199-233.- 12. Гуревич П. С., Осипов А.И., Никитина Л. В., Садыков Б. Г.// Родовые травмы и повреждения новорожденных.- Воронеж, 1982.- 13. Дергачев B. В., Полетаев А. Б., Наумова T. С., Шели хов В. Н. // В кн.: Функции нейроглии. - Тбилиси, Мецниереба, 1979.- 14. Зубцова Н. T.// Об иммунологических показателях церебральной патологии плода и новорожденного.Автореф. канд. дисс.- М., 1973.- 15. Ильяшевич В. И.// Значение тканевой ауто- и изосенсибилизации рожениц в развитии асфиксии плода и новорожденного. - Автореф. канд. робяну, Ш. Берчану. Иммунобиология, иммунохимия, иммунопатология. / Под ред. И. МесГемолитическая болезнь Изд-во Академии наук Румынии, 1977.- 17. Козлов Л. А.// В кн.: 
зань, 1978.- Т. 50.- С. 7-15.- 18. Коновалов Г. В., Родштейн О. А. // В кн.: Культура нервной ткани. / Под ред. Ю. М. Жаботинского.- М., 1977.-. 19. Конокотина Г. Ф.//В кн.: Иммунопатология нервных и психических заболеваний.- Тез. докл. Всесоюзн. научн. конф.М., 1983.- 20. Майзелис М. Я.// В кн.: Гисто-гематические барьеры и нейрогуморальная регуляция.- М., Наука, 1981.- 21. Морозов Г. В.//В кн.: Иммунопатология нервных и психических заболеваний. - Тез. докл. Всесоюзн. научн. конф.- М., 1983.- 22. Осна А. И.// В кн.: Актуальные вопросы неврология и нейрохирургии новорожденных.-- Тез. Всерос. симпоз.- Новокузнецк, 1980.- 23. Осна А. И., Батманова В. В., Батманоя И. В. // Там же.24. Персианинов Л. С. // Асфиксия плода и новорожденного.- М., Медицина, 1967.- 25. Петренко С. Е., Шелихов В. Н., Наумова Т. С. и др. // В кн.: Функции нейроглии.- Тбилиси, 1979. - 26. Петров Р. В. // Иммунология.- М., Медицина, 1982._ 27. Полетсев А. Б. // О роли нейроглии в системной деятельности организма.- Автореф. канд. дисс.- М., 1977.28. Равкина Л. И., Горюнова А. Г. // Невропатол. и психиатр. - 1976.- № 7.- С. 978983.-29. Ратнер А. Ю. // Казанский мед. ж.- 1982.-№ 4.- С. 30-32.- 30. Ратнер А. Ю.// Родовые повреждения нервной системы.- Казань, 1985. - 31. Савельева Г. М., Антонова Л. В., Прозоровская К. Н. // Значение иммунологических исследований в акушерстве и гинекологии. - Ташкент, Медицина, 1981.- 32. Садыков Б. Г., Бородин Ю. И.// В кн.: Иммунопатолия нервных и психических заболеваний.- Тез. докл. Всесоюзн. научн. конф.М., 1983.- 33. Сверановская В. В., Гервазиева В. Б. // В кн.: Нейроиммунология в клинике и эксперименте.- Труды Моск. НИИ психиатрии.- М., 1975. - Т. 69.- С. 317-321.34. Семенов А. С. // В кн.: Иммунология нервных и психических заболеваний.- Тез. докл. на Пленуме правления Всесоюзн. научн. общества невропат. и психиатров.- М., 1974.35. Семенов А. С. // Иммунологические факторы в развитии перинатальной патологии моз- Автореф. канд. дисс.- М., 1982.- 36. Семенов А. С., Торбек В. Э.// В кн.: Иммунопатология нервных и психических заболеваний.- Тез. докл. Всесоюзн. научн. конф.- М., 1983.-37. Семенов С. Ф. // В кн.: Врожденная патология мозга в клинике и патогенезе нервно-психических расстройств. - Труды Моск. НИИ психиатрии. / Под общ. ред. С. Ф. Семенова.- М., 1979.- Т. 89.- С. 9-23.- 38. Семеноя С. Ф.// В кн.: ІІ Всесоюзный симпозум по иммунологии воспроизведения.- Тез. докл.- М., 1980.-39. Семенов С. Ф.// Невропатол. и психиатр. - 1981.- № 4.- С. $602-605-40$. Семеноя С. Ф. // В кн.: Иммунопатология нервных и психических заболеваний.- Тез. докл. Всесоюзн. научн. конф.М., 1983.- 41. Семенов С. Ф., Назаров К. Н., Чуприков А. П. // Аутоиммунные процессы при врожденных энцефалопатиях, эпилепсии и шизофрении.- М., Медицина, 1973.-42. С $e$ менов С. Ф., Майзелис М. Я., Гвирцман Л. Е.// В кн.: Нейроиммунология в клинике и жсперименте.- Труды Моск. НИИ психиатрии.- М., 1975.- Т. 69.-С. 357-362.-43. Сeменов С. Ф., Семенова К. А., Могилина Н. П. и др. В кн.: Иммунология размножения.-Труды III Международн. симпоз.- Варна - София, 1978. - 44. Семеноя С. Ф., Семенова K. A.// Иммунобиологические основы патогенеза нервных и психических заболеваний.Ташкент, Медицина, 1984.- 45. Семенова K. A.// В кн.: Нейроиммунология в клинике и жсперименте.- Труды Моск. НИИ психиатрии - М., 1975.- Т. 69.- С. 172-181.-46. Семенова K. A.// В кн.: Актуальные вопросы неврологии и нейрохирургии новорожденных.Тез. Всерос. симпоз.- Новокузнецк, 1980.- 47. Семенова K. А.// В кн.: Иммунопатология нервных и психических заболеваний. - Тез. докл. Всесоюзн. научн. конф.- М., 1983.48. Семенова К. А., Батманова В. В., Батманов И. В.// В кн.: Нейроиммунология в клинике и эксперименте.- Труды Моск. НИИ психиатрии.- М., 1975.- Т. 69.- С. 182-192.49. Сухорукова Л. И. / Невропатол. и психиатр.- 1976.- № 5.- С. $692-697$. - 50. Трекова Н. A.// В кн.: Врожденная патология мозга в клинике и патогенезе нервно-психических расстройств.- Труды Моск. НИИ психиатр./Под общ. ред. С. Ф. Семенова.- М., 1979.Т. 89.- С. 68-74.- 51. Трекова H. A.// Особенности функции гемато-энцефалического барьера и синтеза белков в разных отделах мозга крыс, подвергшихся нейроиммунизации, и их потомства.- Автореф. канд. дисс.-- М., 1983.- 52. Фолк У. П., Джонсон П. М.// В кн.: Последние достижения в клинической иммунологии.- Перев. с англ./Под ред. Р. А. Томпсона. - М.. 1983.- 53. Фонталин Л. Н., Певницкий Л. А. // Иммунологическая толерантность-- М., Медицина, 1978.-54. Хасаноя А. А., Дазыдова М. А. // Казанский мед. ж.1981.- № 4.- С. 27-30.- 55. Царегородцева T. М. // Нейроаллергия.- М., Медицина, 1972.- 56. Штарк М. Б. // Иммунонейрофизиология.-- Л., Медицина, 1978.-57. Bornstein M. B., Grain S. M. // Science-1965. - Vol. 148.- P. 60-62. 